\title{
Intraorifice sealing ability of different materials in endodontically treated teeth
}

\author{
María-Estela Bailón-Sánchez ${ }^{1}$, Silvia González-Castillo ${ }^{1}$, María-Paloma González-Rodríguez ${ }^{1}$, Rafael Poya- \\ tos-Martínez ${ }^{2}$, Carmen-María Ferrer-Luque ${ }^{1}$
}

\begin{abstract}
${ }^{1}$ BDS, BDS, Graduate in Dentistry, Department of Dental Pathology and Therapeutics, School of Dentistry, University of Granada (Spain)

DDS, PhD, Contracted Professor, Department of Dental Pathology and Therapeutics, School of Dentistry, University of Granada (Spain)

DDS, MD, PhD, Associate Professor, Department of Dental Pathology and Therapeutics, School of Dentistry, University of Granada (Spain)

${ }^{2} \mathrm{PhD}$, Clinical Analysis Service, Hospital Virgen de las Nieves, Granada (Spain)
\end{abstract}

Correspondence:

Department of Dental Pathology and Therapeutics,

School of Dentistry, University of Granada, Spain,

Campus de Cartuja,

Colegio Maximo $s / n$,

18071 Granada, Spain

cferrer@ugr.es

Bailón-Sánchez ME, González-Castillo S, González-Rodríguez MP, Poyatos-Martínez R, Ferrer-Luque CM. Intraorifice sealing ability of different materials in endodontically treated teeth. Med Oral Patol Oral Cir Bucal. 2011 Jan 1;16 (1):e105-9.

http://www.medicinaoral.com/medoralfree01/v16i1/medoralv16ilp105.pdf

Received: 23-02-2010

Accepted: 31-05-2010

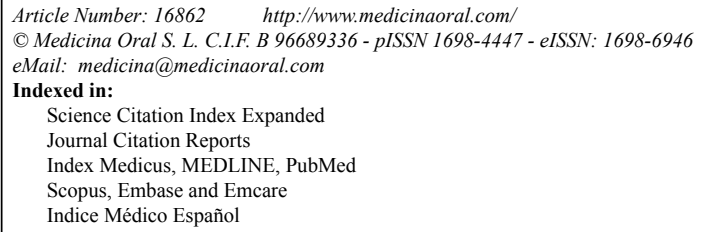

\begin{abstract}
Objectives: To evaluate Cavit ${ }^{\mathrm{TM}} \mathrm{G}$, ProRoot ${ }^{\mathrm{TM}}$ MTA and Tetric ${ }^{\circledR}$ EvoFlow as intraorifice barriers to prevent coronal microleakage in root canal treatment.

Study Design: Forty-two human single rooted teeth were divided randomly in three experimental groups of 10 specimens each and two control groups. The experimental groups were prepared with hand instrumentation and cold lateral condensed technique of the gutta-percha. Four millimetres of coronal gutta-percha were removed and replaced by one of the following filling materials: Cavit ${ }^{\mathrm{TM}} \mathrm{G}$, Tetric ${ }^{\circledR}$ EvoFlow or ProRoot ${ }^{\mathrm{TM}}$ MTA. In the experimental groups, leakage was measured by the concentration of leaked glucose in the apical reservoir at 1, 7, 30, and 45 days, using the enzymatic glucose oxidase method. Data were analyzed by means of Mann-Whitney U and Kruskal-Wallis tests at $\alpha=0.05$.

Results: The glucose penetration results of three experimental groups increased gradually over time. No significant differences were found among groups at 24 hours and 1 week. At thirty and forty-five days, Cavit ${ }^{\mathrm{TM}}$ and Tetric $^{\circledR}$ EvoFlow values were significantly different ( $\mathrm{p}=0.007$ and $\mathrm{p}=0.023$, respectively).

Conclusions: The sealing ability of the Cavit ${ }^{\mathrm{TM}} \mathrm{G}$, ProRoot ${ }^{\mathrm{TM}}$ MTA and Tetric ${ }^{\circledR}$ EvoFlow used as intraorifice materials tends to be similar over time.
\end{abstract}

Key words: Cavit ${ }^{\mathrm{TM}} G$, coronal microleakage, glucose penetration model, intraorifice barrier, Tetric ${ }^{\circledR}$ EvoFlow, ProRoot $^{\mathrm{TM}}$ MTA. 


\section{Introduction}

The basic purpose of filling root canals is to obtain total root canal system isolation from the oral environment, in order to prevent bacterial leakage (1). Prevention of coronal leakage in root canal therapy can be accomplished by temporary restorative materials. However, a loss of the temporary material of restoration, a delay in placing the definitive restoration or an alteration of the coronal seal of both restorations would promote the coronal leakage of bacteria (2). Complete bacterial penetration has been demonstrated in vitro (3) and in vivo (4) through root canal filling in teeth without temporary restoration.

According to the type of material used and exposure time to the oral cavity, all temporary materials leak to some extent (5-8), and the degree to which different temporary filling materials are capable of establishing and maintaining a good coronal seal is often questioned (9). The use of a material to seal the orifice, in addition to temporary restoration after root canal filling, has been recommended as a supplementary layer of protection for the obturated canal (7). Different studies have shown that materials such as Cavit ${ }^{\mathrm{TM}}$, Composite, ProRoot $^{\mathrm{TM}}$ MTA, IRM ${ }^{\circledR}$; Super-Eba ${ }^{\circledR}$, etc., placed at a depth from 1 to $4 \mathrm{~mm}$, are beneficial in preventing coronal microleakeage because they act like intraorifice barriers in root canal filling $(4-7,10)$.

Recently, a model that effectively measures the leakage of glucose molecules has been proposed $(11,12)$. It is based on measurements of glucose concentrations in an apical chamber using a sensitive enzymatic reaction. A coloured substance is produced, and optical density (OD) is determined by a spectrophotometer, translated later to concentration units. The advantages of this model are its ease of assembly and operation, the availability of the materials and equipment, and the high sensitivity of the test (12).

The purpose of this study was to evaluate the sealing ability of Cavit ${ }^{\mathrm{TM}}$ G, ProRoot ${ }^{\mathrm{TM}}$ MTA and Tetric ${ }^{\circledR}$ EvoFlow as intraorifice barriers using a leakage glucose model. The null hypothesis to be tested is that there are no differences in microleakage values when using the different tested materials at various time periods.

\section{Material and Methods}

\section{Selection and preparation of teeth}

Forty-two extracted teeth were selected for this study. Roots with cracks, open apices, resorptive defects, or large carious lesions approaching the pulp were excluded. After removal of debris, calculus and soft tissues on the root surface, the teeth were stored in $2 \%$ thymol solution until use. Crowns were removed at the cementum-enamel junction level using an Accutom50 diamond cutter (Accutom Hard Tissue Microtome, Struers, Ballerup, Denmark) under copious water cooling, to obtain root specimens $15 \mathrm{~mm}$ in length.

\section{Root canals preparation}

All the teeth were instrumented by the same operator. After removal of the pulp tissue using a barbed broach, a \#15 K file (Dentsply-Maillefer, Ballaigues, Switzerland) was introduced into the root canal until the tip was just visible at the major apical foramen. The working length was determined by subtracting $1 \mathrm{~mm}$ from this length. Apical patency was confirmed by inserting a \#15 file through the apical foramen before and after preparation. The root canals were prepared sequentially until \#15 to \#40 K-Flexofile file (Dentsply Maillefer Instruments, Ballaigues, Switzerland) and were irrigated with $2 \mathrm{~mL}$ freshly prepared $2.5 \%$ sodium hypochlorite solution after each change of instrument. A final rinse with $5 \mathrm{~mL}$ of $25 \%$ citric acid and $5 \mathrm{~mL}$ purified water was used to remove the other irrigants, and the specimens were then dried with paper points.

The experimental root canals $(\mathrm{n}=30)$ were filled using the cold lateral condensed gutta-percha technique (Dentsply Maillefer Instruments, Ballaigues, Switzerland) and AH Plus ${ }^{\mathrm{TM}}$ Jet Mixing Syringe (DeTrey/ Dentsply Konstanz, Germany) sealer, mixed according to manufacturers' instructions. The accessory guttapercha cones were lightly coated with sealer and placed in the canal, using cold lateral compaction. The process was repeated until the cone could not be inserted more into the canal. The excess of gutta-percha was removed with a hot plugger $(0.5 \mathrm{~mm}$ diameter, Dentsply Maillefer Instruments, Ballaigues, Switzerland) and vertically compacted. In the positive control group $(n=6)$ canals were filled using gutta-percha cones without sealer or intraorifice barriers. Negative controls $(n=6)$ were sealed with laterally compacted gutta-percha and $\mathrm{AH}$ Plus $^{\mathrm{TM}}$, and intraorifice barriers and were completely covered with nail polish varnish.

Orifice plug placement

A System B heat source with a 40/06 plugger (SybronEndo, Orange, CA) was used to remove the four coronal millimetres of the filling material, and depth was verified using a periodontal probe (Hu-Friedy Europe, Leimen, Germany). Excess sealer was removed with cotton pellets soaked in 70\% isopropyl alcohol. The ProRoot ${ }^{\mathrm{TM}}$ MTA original (DeTrey/Dentsply, Konstanz, Germany), Cavit $^{\text {TM }}$ G (3M ESPE, Seefeld, Germany) materials were put into the orifice according to manufacture's directions. For the Tetric ${ }^{\circledR}$ EvoFlow (Ivoclar/Vivadent, Schaan, Liechtenstein), the specimens were etched with $37 \%$ phosphoric acid for 15 seconds, washed for $10 \mathrm{sec}-$ onds, then gently dried with cotton pellets. Afterwards, Primer\&Bond ${ }^{\circledR}$ NT (DeTrey/Denstply. Konstanz, Germany) was applied to the dentin using a saturated disposable brush. The excess was removed by an air spray (5 seconds), and it was then cured with a visible light activator (Bluephase. Ivoclar/Vivadent. Schaan, Liechtenstein) for 10 seconds. Tetric ${ }^{\circledR}$ EvoFlow was condensed 
until the cavity was filled, after which it was cured with a visible light activator for 30 seconds. Each root was placed in a coded container and stored at humidity for 48 hours to allow the materials to set.

Glucose penetration model

The roots (thirty experimental teeth and twelve controls) were mounted on a glucose leakage modified model (12). Then, $100 \mu$ of solution was drawn from a glass bottle using a micropipette immediately afterwards, and at 24 hours, 7, 30 and 45 days. The same amount of fresh sterile water was added to the glass bottle to maintain a constant volume of $2 \mathrm{~mL}$. The sample was then analysed using a Glucose kit (Gluco-quant Glucose/HK, Roche/Hitachi 917/ACN 549. Roche Diagnostics, Basel, Switzerland), in a Modular System Autoanalyzer (Roche Diagnostics, Basel, Switzerland), at a wavelength of $340 \mathrm{~nm}$. The concentrations of the glucose were expressed in mmol L-1 at each time interval.

Statistical analysis

Mean and standard deviations were determined for each group. The Shapiro-Wilk test was used to check the normality of data distribution. As the results for each group did not follow a normal distribution, the variables were analyzed using a nonparametric test. After KruskalWallis test the Mann-Whitney U test was used for pair- wise comparisons of the mean glucose leakage values. The level of statistical significance was set at $p<0.05$. All statistical analyses were performed using SPSS 15.0 software (SPSS Inc, Chicago, IL).

\section{Results}

The microleakage results are presented in Table 1 and Fig. 1. The amount of glucose penetration of the three experimental groups increased gradually over time. The lowest glucose leakage that the current procedure is able to detect is $2 \mathrm{mg} / \mathrm{dL}(0.11 \mathrm{mmol} \mathrm{L}-1)$, lower readings were not reported (missing values).

At the first day, the leaked glucose values ranged between $2.75 \mathrm{mmol} / \mathrm{L}-1$ for Cavit ${ }^{\mathrm{TM}} \mathrm{G}$ and $3.38 \mathrm{mmol} / \mathrm{L}-1$ for ProRoot ${ }^{\mathrm{TM}}$ MTA. At the end of the evaluation period, the microleakage values detected with the three intraorifice sealing materials were $8.26 \mathrm{mmol} / \mathrm{L}-1$ (Cavit ${ }^{\mathrm{TM}} \mathrm{G}$ ), $8.44 \mathrm{mmol} / \mathrm{L}-1$ (Tetric ${ }^{\circledR}$ EvoFlow) and 8.61 $\mathrm{mmol} / \mathrm{L}-1$ (ProRoot ${ }^{\mathrm{TM}} \mathrm{MTA}$ ). No significant differences were found among materials at 24 hours and 1 week. At thirty and forty-five days, the values of glucose penetration differed significantly among the three groups: for both evaluation times, Cavit ${ }^{\mathrm{TM}} \mathrm{G}$ and Tetric $^{\circledR}$ EvoFlow results showed significant differences $(\mathrm{p}=0.007$ and $\mathrm{p}=0.023$, respectively).

Table 1. Penetration glucose values in mmol L-1 at different time periods (mean and standard deviations).

\begin{tabular}{|c|c|c|c|c|}
\hline \multicolumn{5}{|c|}{ Glucose leakage } \\
\hline Materials & 1 day & 7 days & $\mathbf{3 0}$ days & $\mathbf{4 5}$ days \\
\hline ProRoot & \\
\hline Cavit $^{\mathrm{TM}}$ GTA & $3.38 \pm 3.72$ & $7.21 \pm 3.67$ & $8.49 \pm 0.01$ & $8.61 \pm 0.01$ \\
\hline Tetric $^{\circledR}$ EvoFlow & $3.08 \pm 2.92$ & $6.32 \pm 3.82$ & $7.20 \pm 2.08^{\mathrm{a}}$ & $8.44 \pm 1.01^{\mathrm{a}}$ \\
\hline
\end{tabular}
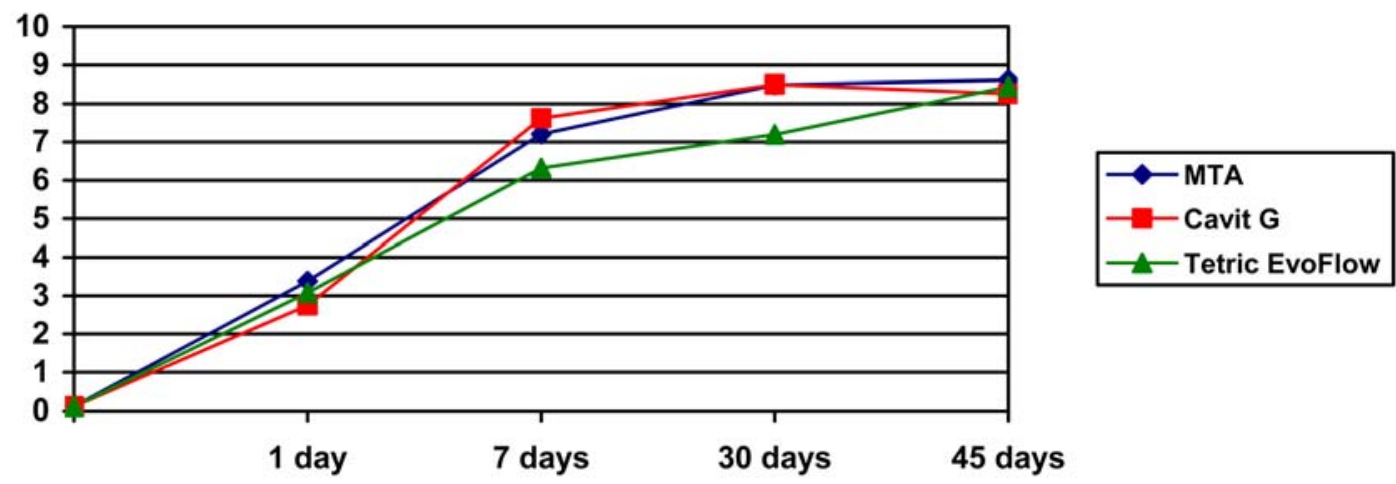

Fig. 1. Mean glucose penetration in mmol L-1 over time. 


\section{Discussion}

The maintenance of a durable seal of the root canal system is necessary to prevent leakage, and coronal restoration is an important requisite for long-term endodontic success $(2,3)$. Restorative materials should provide a permanent, leak-proof seal. Defective temporary or permanent restoration during or after root canal treatment is a main cause of coronal leakage (13).

Traditionally, the prevention of coronal leakage while the final coronal restoration is underway is achieved using temporary materials, which have their limitations. For this reason the coronal part of the root canal must be sealed as closely as possible. The use of a material as an intraorifice barrier could mitigate bacterial filtration if the restoration were lost or unsuitable (7).

A variety of experimental models may be used to measure the filtration through filled roots; they include dye penetration (14), fluid transport (15) and bacterial penetration (16). In the present study, glucose penetration (11) was used. Benefits of the glucose penetration model are attributed to the tracer, the possibility of quantitative measurements, reproducibility, and sensitivity $(11,12)$. Glucose is used as a tracer because it is hydrophilic, has a molecular weight lower than bacteria (MW=180 Da) and serves as a nutrient for bacteria (17). With this method, the cumulative amount of glucose leaking through the interface of intraorifice barriers in root canal fillings may be monitored at various time points (18). We measured the levels of glucose penetration at 1 , 7, 30 and 45 days, frequent time intervals for endodontic treatment or when permanent restoration is carried out after root canal treatment (10).

Although previous research supports the effectiveness of intraorifice barriers, there is no consensus as to the protocol or material used as the coronal barrier after root canal treatment (6). Different depths have been tested, and the studied materials include Cavit ${ }^{\mathrm{TM}}, \mathrm{IRM}^{\circledR}$, TERM $^{\circledR}$ and Tetric $^{\circledR}$ EvoFlow $(5,8)$. The intraorifice barrier thickness most recommended to date is 3 to 4 millimetres $(5,6,8)$. This depth would seal the canal appropriately without limiting the volume or compromise retention of the final restoration.

The null hypothesis should be only partially accepted as the three materials tested in our study exhibited very similar behaviour over the 45 days period. An increase of glucose penetration is observed during the first week. Then, between day 7 and day 45, glucose penetration values showed few changes. Tetric ${ }^{\circledR}$ EvoFlow was the material that showed the least penetration between 7 and 30 days; but after 30 days it showed a progressive increase in filtration, reaching the values of the other two materials at 45 days. Although there were significant differences between Tetric ${ }^{\circledR}$ EvoFlow and Cavit ${ }^{\mathrm{TM}}$ at 30 and 45 days, the clinical significance of these differences, in terms of absolute values, is not relevant.
Cavit ${ }^{\mathrm{TM}} \mathrm{G}$ sealed better at 24 hours of its application, a finding that might be attributed to water absorption and its expansion during setting (19). Sauaia et al. (8) also reports Cavit ${ }^{\mathrm{TM}} \mathrm{G}$ to provide the best intraorifice sealing according to stereomicroscope evaluation, as compared with Vitremer ${ }^{\mathrm{TM}}$ and flowable composite Flow-It, after 5 days of immersion in dye. Using bacterial filtration and a greater time of evaluation (90 days), Pisano et al. (5) found that Cavit ${ }^{\mathrm{TM}}$ sealed significantly better than Intermediate Restorative Material $\left(\mathrm{IRM}^{\circledR}\right)$ and Super$\mathrm{Eba}^{\circledR}$ when used, as intraorifice filling materials.

In this study, Tetric ${ }^{\circledR}$ EvoFlow gave the lowest glucose penetration values at 7 and 30 days, in line with the results of Jenkins et al. (7). These authors evaluated the sealing capacity of Cavit ${ }^{\mathrm{TM}}$, ProRoot ${ }^{\mathrm{TM}}$ MTA and Tetric $^{\circledR}$, at thicknesses of $1,2,3$ or $4 \mathrm{~mm}$, with Indian ink during seven days. It was shown that Tetric $^{\circledR}$ leaked less than Cavit ${ }^{\mathrm{TM}}$ or ProRoot ${ }^{\mathrm{TM}}$ MTA, regardless of the applied thickness, and the ProRoot ${ }^{\mathrm{TM}}$ MTA did not attain better results than the others materials after intraorifice sealing evaluation. Shemesh et al. (20) argued that one of the ProRoot ${ }^{\mathrm{TM}}$ MTA components $\left(\mathrm{Ca}(\mathrm{OH})_{2}\right)$ could react directly with glucose and thus mask leakage, though we did not find lower ProRoot ${ }^{\mathrm{TM}}$ MTA values with this model.

\section{Conclusion}

Within the limitations of the present study, using the glucose penetration model, Cavit ${ }^{\mathrm{TM}} \mathrm{G}$, Tetric ${ }^{\circledR}$ EvoFlow or ProRoot ${ }^{\mathrm{TM}}$ MTA attained similar leakage values when used as intraorifice barriers regarding of the testing period.

\section{References}

References with links to Crossref - DOI

1. Schwartz RS, Fransman R. Adhesive dentistry and endodontics: materials, clinical strategies and procedures for restoration of access cavities: a review. J Endod. 2005;31:151-65.

2. Saunders WP, Saunders EM. Coronal leakage as a cause of failure in root-canal therapy: a review. Endod Dent Traumatol. 1994;10:105-8.

3. Swanson K, Madison S. An evaluation of coronal microleakage in endodontically treated teeth. Part I. Time periods. J Endod. 1987;13:56-9.

4. Galvan RR Jr, West LA, Liewehr FR, Pashley DH. Coronal microleakage of five materials used to create an intracoronal seal in endodontically treated teeth. J Endod. 2002;28:59-61.

5. Pisano DM, DiFiore PM, McClanahan SB, Lautenschlager EP, Duncan JL. Intraorifice sealing of gutta-percha obturated root canals to prevent coronal microleakage. J Endod. 1998;24:659-62.

6. Wolcott JF, Hicks ML, Himel VT. Evaluation of pigmented intraorifice barriers in endodontically treated teeth. J Endod. 1999;25:589-92.

7. Jenkins S, Kulild J, Williams K, Lyons W, Lee C. Sealing ability of three materials in the orifice of root canal systems obturated with gutta-percha. J Endod. 2006;32:225-7.

8. Sauáia TS, Gomes BP, Pinheiro ET, Zaia AA, Ferraz CC, SouzaFilho FJ. Microleakage evaluation of intraorifice sealing materials in endodontically treated teeth. Oral Surg Oral Med Oral Pathol Oral Radiol Endod. 2006;102:242-6.

9. Barrieshi-Nusair KM, Hammad HM. Intracoronal sealing com- 
parison of mineral trioxide aggregate and glass ionomer. Quintessence Int. 2005;36:539-45.

10. Mavec JC, McClanahan SB, Minah GE, Johnson JD, Blundell RE Jr. Effects of an intracanal glass ionomer barrier on coronal microleakage in teeth with post space. J Endod. 2006;32:120-2.

11. Xu Q, Fan MW, Fan B, Cheung GS, Hu HL. A new quantitative method using glucose for analysis of endodontic leakage. Oral Surg Oral Med Oral Pathol Oral Radiol Endod. 2005;99:107-11.

12. Shemesh $\mathrm{H}, \mathrm{Wu}$ MK, Wesselink PR. Leakage along apical root fillings with and without smear layer using two different leakage models: a two-month longitudinal ex vivo study. Int Endod J. 2006;39:968-76.

13. Chong BS. Coronal leakage and treatment failure. J Endod. 1995;21:159-60.

14. Camilleri J, Pitt Ford TR. Evaluation of the effect of tracer pH on the sealing ability of glass ionomer cement and mineral trioxide aggregate. J Mater Sci Mater Med. 2008;19:2941-8.

15. Cobankara FK, Orucoglu H, Sengun A, Belli S. The quantitative evaluation of apical sealing of four endodontic sealers. J Endod. 2006;32:66-8.

16. Celik EU, Yapar AG, Ateş M, Sen BH. Bacterial microleakage of barrier materials in obturated root canals. J Endod. 2006;32:1074-6. 17. Wu MK, Wesselink PR. Endodontic leakage studies reconsidered. Part I. Methodology, application and relevance. Int Endod J. 1993;26:37-43.

18. Xu Q, Ling J, Cheung GS, Hu Y. A quantitative evaluation of sealing ability of 4 obturation techniques by using a glucose leakage test. Oral Surg Oral Med Oral Pathol Oral Radiol Endod. 2007;104:e10913.

19. Lai YY, Pai L, Chen CP. Marginal leakage of different temporary restorations in standardized complex endodontic access preparations. J Endod. 2007;33:875-8

20. Shemesh H, Souza EM, Wu MK, Wesselink PR. Glucose reactivity with filling materials as a limitation for using the glucose leakage model. Int Endod J. 2008;41:869-72. 